\title{
Perception and production of the vowel length contrast in Japanese by native speakers of Brazilian Portuguese
}

\author{
Luan A. Fazolin^, Plinio A. Barbosa
}

\begin{abstract}
The aim of this investigation is to observe if and how native speakers of Brazilian Portuguese who study Japanese as a foreign language perceive and produce the Japanese vowel length contrast, such as in "jisho", dictionary, and "jishou", phenomenon or event. In order to do so, the subjects will participate in two experiments: a two-alternative forced choice test (to measure perception) and a reading task (to observe production). The experiments will be applied in August and September/2019, so by the time of the congress there will be partial results.
\end{abstract}

\section{Key words: \\ Experimental phonetics, Foreign language learning, Length contrast.}

\section{Introduction}

The length contrast is an important aspect of the Japanese language. It occurs both in consonants, opposing, e.g., /kita/, came, and /kit:a/, cut or sliced and in vowels, /obasan/, aunt, and /obaasan/, grandmother. Perceiving and producing minimal pairs such as those is fundamental to satisfactorily comprehend and to be comprehended, be it in one's native language, be it in one's second or foreign language.

In that direction, models such as the Speech Learning Model $^{1}$ and the Perceptual Assimilation Model $^{2}$ were developed to summarize how these abilities are linguistically and cognitively acquired and to predict interlinguistic influence and interaction. Despite fundamental theoretical differences, both models assume that we have one common phonetic-phonological space, shared by every language we know and use, and that the interaction's effects might be predicted, especially when the native language's phonetic and phonological systems are considered.

That all being said, through two experiments (a perception and a production experiment), the objectives of the present study consist in investigating whether native speakers of Brazilian Portuguese who study Japanese can perceive and produce the length contrast in the vowels, and if they do, how accurately. In doing so, we aim to develop both our understanding of these processes and the refinement of the models considered above, at the same time considering the specialties of the Brazilian contexts of foreign language learning.

\section{Results and Discussion}

There were 30 participants in the experiment, divided into 3 groups: one with students who had just started learning Japanese, one with students who had learnt Japanese for 1 year and other who had learnt it for 2 years. All 30 participants took part in both experiments and answered two questionnaires, one regarding their familiarity with the vocabulary used in the experiments and another one regarding their linguistic contact with Japanese and their motivation in learning Japanese. This way, besides investigating the ifs and hows of perception and production, the results obtained will also contribute to the understanding of other very important topics, e.g., the correlation between perception and production, the development of these abilities throughout a formal language course, the individual differences in performance, the effects of dmotivation etc.
As said before, two experiments were developed: one to measure perception and the other to measure production. The perception experiment was a two-alternative forced choice test with audio stimuli, in which participants were exposed to a target word in the carrier sentence kore ha desu (this is ) and then had to choose between a minimal pair to fill in the gap. Since there are 5 vowels in Japanese and the length contrast occurs in all 5 vowels, 20 disyllables (or 10 minimal pairs) were chosen as target words, so that the phenomena could also be observed in word initial and final positions. There were $2 / 3$ of distractors and 2 repetitions, totalizing 180 sentences.

The production experiment followed the perception experiment and was divided into two phases; in the first phase the participants read aloud the sentences they had listened to in the perception experiment, without yet being aware of the study's target words. In the second phase, they had to read aloud the sentences again - this time, only the sentences containing the target words - , but being instructed about the studied phenomena. This way, the production experiment generated two sets of data: one before and one after instruction.

\section{Conclusions}

Since the experiments will be applied in August and September/2019, there are still no results while this summary is being written (July/2019). This also means that by the time of the congress there will be partial results, including statistical analysis of the data collected. Nonetheless, our main hypothesis is that most participants will be able to perceive and produce the length contrast, but with a significantly higher standard deviation when compared to native speakers', just as found in another study 3 .

\section{Acknowledgement}

This study is being funded by FAPESP (\#2018/14753-4).

\footnotetext{
${ }^{1}$ Flege, J. E. Second language speech learning: Theory, findings and problems Speech perception and linguistic experience: Issues in cross-language research. 1995, 233-277, 92.

2 Best, C. T. Chapter 6: A Direct Realist View of Cross-Language Speech Perception. Speech perception and linguistic experience: Issues in crosslanguage research. 1995, 171-204, 92.

${ }^{3}$ Cato, A.; Cox, F. Development of Japanese length contrast: A longitudinal study of L2 vowels, produced by Australian learners of Japanese. 2006, 170175 .
} 